Am. J. Trop. Med. Hyg., 73(1), 2005, pp. 214-221

Copyright (C) 2005 by The American Society of Tropical Medicine and Hygiene

\title{
USE OF RAINFALL AND SEA SURFACE TEMPERATURE MONITORING FOR MALARIA EARLY WARNING IN BOTSWANA
}

\author{
MADELEINE C. THOMSON,* SIMON J. MASON, THANDIE PHINDELA, AND STEPHEN J. CONNOR \\ International Research Institute for Climate Prediction, The Earth Institute at Columbia University, New York, New York; National \\ Malaria Control Programme, Epidemiology and Disease Control Unit, Ministry of Health, Gaborone, Botswana
}

\begin{abstract}
Improved prediction, prevention, and control of epidemics is a key technical element of the Roll Back Malaria partnership. We report a methodology for assessing the importance of climate as a driver of inter-annual variability in malaria in Botswana, and provide the evidence base for inclusion of climate information in a national malaria early warning system. The relationships of variability in rainfall and sea surface temperatures (SSTs) to malaria incidence are assessed at the national level after removing the impact of non-climatic trends and a major policy intervention. Variability in rainfall totals for the period December-February accounts for more than two-thirds of the inter-annual variability in standardized malaria incidence in Botswana (January-May). Both rainfall and annual malaria anomalies in December-February are significantly related to SSTs in the eastern Pacific, suggesting they may be predictable months in advance using seasonal climate forecasting methodologies.
\end{abstract}

\section{INTRODUCTION}

Epidemic malaria is a serious scourge of semi-arid and highland areas in Africa. Epidemics occur among vulnerable populations where host immunity to malaria is often nonexistent or poorly developed. It is estimated that epidemic malaria causes between $12 \%$ and $25 \%$ of estimated annual worldwide malaria deaths including up to $50 \%$ of the estimated annual malaria mortality in persons less than 15 years of age. ${ }^{1}$

Rainfall anomalies are widely considered to be a major driver of inter-annual variability of malaria incidence in the semi-arid areas of Africa ${ }^{2}$ and are therefore included by the Roll Back Malaria Technical Support Network for Epidemic Prevention and Control as one of the key indicators for the development of malaria early warning systems. ${ }^{3}$ The goal of Roll Back Malaria is to halve the burden of malaria by 2010. A series of targets for realizing this goal in Africa was set at the Abuja Malaria Summit in April 2000, which included the target that $60 \%$ of epidemics be detected within two weeks of onset. $^{4}$

Analyses of time-series malaria and climate data have been conducted over the last century in many parts of the world, and have indicated that rainfall excess (or occasionally drought) is correlated with changes in malaria incidence in certain eco-epidemiologic settings, ${ }^{2}$ apparently as a result of its impact on the population dynamics of the Anopheles spp. mosquito vector. ${ }^{5}$ While there are well-recognized causal relationships between rainfall and malaria transmission (creation of breeding sites favors larger numbers of juvenile, and therefore adult, mosquitoes; increased humidity favors vector survival) the relationship is often non-linear with excessive rainfall sometimes even resulting in less malaria than expected. ${ }^{6}$ There are a number of explanations for this nonlinearity. ${ }^{7}$ The most widely cited is that excessive rainfall may wash out breeding sites, but other possible factors may be important, such as increased host protection in the light of changes in risk perception, density-dependent vector-host interaction, and possible reductions in temperature, which may

\footnotetext{
* Address correspondence to Madeleine C. Thomson, International Research Institute for Climate Prediction, The Earth Institute at Columbia University, Monell Building, 61 Route 9W, Lamont Campus, Palisades, NY 10964-8000. E-mail: mthomson@iri.columbia.edu
}

result from high evapotranspiration following a deluge. A converse process has also been observed in some humid areas where drought has increased malaria transmission because it results in pooling of rivers and the creation of breeding sites. In general, however, the perceived wisdom is that in the warm semi-arid lowland areas in Africa, rainfall excess is an important predictor of epidemics. ${ }^{3}$ With this in mind, satellitederived rainfall estimates have been promoted as an effective means for routine epidemic prediction because they provide information over large areas in a spatially organized way. ${ }^{8-10}$ Malaria early-warning systems based on vulnerability assessment and rainfall variability were used in India in the early part of the 20th century. ${ }^{11}$ It is only in recent years, however, that there has been a concerted effort to develop such systems for epidemic prone areas in Africa. ${ }^{2,12-14}$

In some areas of the world where sea surface temperatures (SSTs) in the Pacific (i.e., the El Niño-Southern Oscillation [ENSO]) are important predictors of climate events, ${ }^{15}$ significant correlations between malaria incidence anomalies and SSTs have been observed. ${ }^{16}$

\section{AIMS OF THE STUDY}

The aims of this study were to 1) develop a methodology for disentangling the effects of climate variability and trend from those caused by other non-climate related factors on a time series of malaria incidence data, and 2) assess the impact of rainfall and SST variability on standardized anomalies of annual confirmed malaria incidences for Botswana. Here we report on the findings from this study and their implications for the development of malaria early warning systems in southern Africa.

\section{BOTSWANA}

Botswana is a landlocked country with a total land area of $581,730 \mathrm{~km}^{2}$. It shares borders with Namibia, Zambia, Zimbabwe, and South Africa. The country is mostly comprised of land 1,000 meters above sea level, with substantial tracts of desert, including the Kalahari in the southwestern region. Temperatures in summer are above $35^{\circ} \mathrm{C}$, while winter minimum temperatures can drop to $0^{\circ} \mathrm{C}$ and below with occasional frost at night in the months of June to August. The average annual rainfall (1961-1990) varies from a maximum of ap- 
proximately $650 \mathrm{~mm}$ in the northern part of the country to a minimum of just under $250 \mathrm{~mm}$ in the extreme southwestern region in the Kgalagadi. Although $90 \%$ of the rainfall falls during the summer months (November-April), the country is subject to high inter-annual variability and periodic drought. ${ }^{17}$ The two malaria vectors, Anopheles gambiae s.l (presumably An. arabiensis) and An. funestus were observed in the then Bechuanaland Protectorate by de Meillon in his classic "Anophelini of the Ethiopian Geographical Region." 18

\section{MALARIA CONTROL}

In Botswana, malaria is ranked as one of the major public health problems and as such is included among the infectious diseases reported routinely through the Health Information System $^{19}$ of the Ministry of Health. There is a well-developed National Malaria Control Program that is considered exemplary in the region ${ }^{4,20}$ and supports the following three control activities.

The first is vector control through annual indoor residual house spraying in disease-endemic areas. From 1973 until 1997, this spraying was achieved using DDT. Between 1997 and 1999, Botswana changed from the use of DDT to deltamethrin and lambda-cyhalothrin due to poor availability of quality DDT rather than to insecticide resistance ${ }^{20}$; these two pyrethroids are still in use today.

The second is chemoprophylaxis for target groups during the malaria season. This includes pregnant women in diseaseendemic areas, residents of areas not endemic for malaria traveling to disease-endemic areas, and school children during epidemic outbreaks.

The third is prompt and effective case management including drug therapy to affected individuals. Treatment is provided free of charge. Chloroquine was abandoned as the firstline treatment in 1997 due to increasing resistance and high rates of treatment failure. It was replaced with sulfadoxinepyrimethamine, which remains the recommended first-line choice for uncomplicated malaria cases.

After the devastating regional malaria epidemic of 1996, malaria control was reinvigorated through a range of initiatives ${ }^{19,21}$ that included changing the first-line drug, the introduction of intramuscular quinine at the health post and clinic level, a change in insecticide, and an extension of the spray program to include newly affected districts. The post-1996 period is therefore described here as the policy intervention period.

\section{MATERIALS AND METHODS}

Epidemiologic data. The Botswana Ministry of Health has compiled consistent statistics on malaria incidence since the early 1980s that include national and sub-national data on cases of laboratory-confirmed malaria. In this analysis, epidemiologic and population data were obtained from the Ministry of Health Epidemiology and Disease Control Unit, and the Central Statistics Office in the capital city of Gaborone. We compared national confirmed incidence per 1,000 population for the period 1982-2003 with unconfirmed malaria incidence to test for potential biases in the data over the 22-year period (Figure 1).

Overall these two datasets are highly correlated $\left(\mathrm{R}^{2}=0.74\right.$,

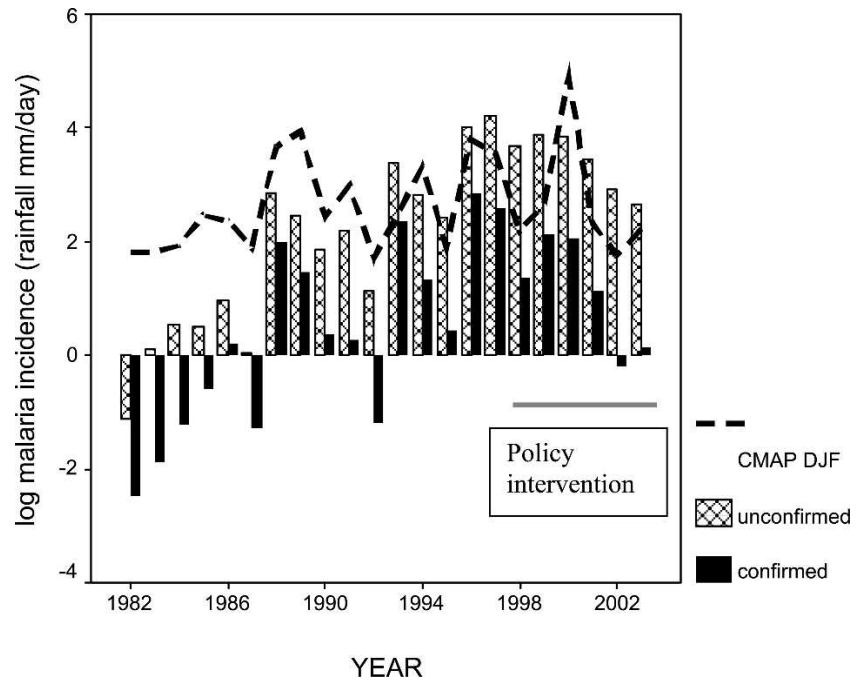

FIGURE 1. Annual log national confirmed and unconfirmed malaria incidence/1,000 population in Botswana and rainfall estimates from Climate Prediction Center Merged Analysis of Precipitation (CMAP), 1982-2003. DJF = December-February.

$P<0.001)$. However, a comparison of the ratio of mean confirmed malaria and unconfirmed incidence pre-intervention and post-intervention period (before and including 1996 and from 1997 onwards) using analysis of variance showed a significant difference $(P=0.007)$. This indicated that a lower proportion of clinical cases was found by laboratory diagnosis to be malaria after the policy intervention rather than prior to it (Figure 2).

Rainfall data. While there are a variety of rainfall datasets for Botswana, few are suitable for analyses of long-term trends and variability. Continuous station-based records are generally available only up to the mid-1990s, but they are characterized by an uneven geographic distribution of gauges in the country. However, satellite-derived estimates of rainfall have an even spatial coverage, and some estimates are available from the late 1970 s to the present time.

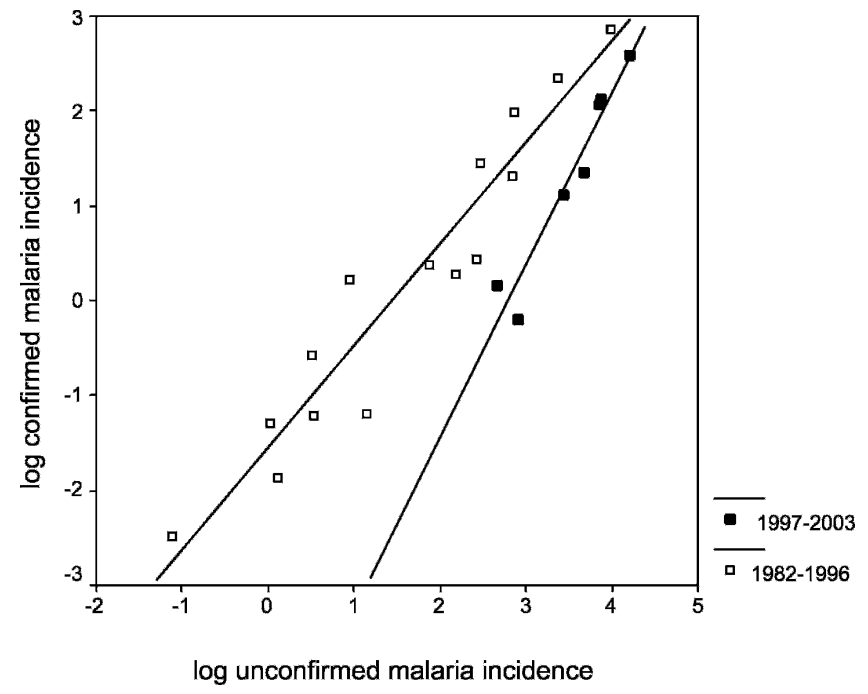

FIGURE 2. Impact of 1997 policy intervention on relationship of confirmed and unconfirmed malaria incidence/1,000 in Botswana, 1982-1996 and 1997-2003. 
The $2.5^{\circ} \times 2.5^{\circ}$ Climate Prediction Center Merged Analysis of Precipitation (CMAP) version $0407^{22}$ is a dataset constructed from gauge observations, five kinds of satellite estimates of precipitation, and from National Centers for Environmental Prediction reanalysis precipitation. Thus, the CMAP data, which are available from 1979 to the present time, are calibrated against available gauge data and dynamical model estimates (reanalyses) and constitute the best estimates of rainfall using all available sources of information (http://www.cpc.ncep.noaa.gov/products/global_precip/html/ wpage.cmap.html). The data are expressed as daily averages (millimeters per day) for each month. These data are of a much coarser spatial resolution than satellite rainfall estimates distributed, for example, by the Africa Data Dissemination Service, ${ }^{8}$ but have the advantage of a consistent time series over the period of study.

Data for the 20 grid areas between latitudes $17.5^{\circ}$ and $27.5^{\circ} \mathrm{S}$ and longitudes $17.5^{\circ}$ and $30.0^{\circ} \mathrm{E}$ were averaged to form estimates of mean monthly rainfall over all of Botswana. Thus, the spatial variability of rainfall within the country was not considered. A set of running three-month seasonal rainfall averages was calculated for the 22 years for months between September and March, when Botswana typically receives more than $90 \%$ of its mean annual rainfall.

Sea-surface temperature data. The ENSO phenomenon is the largest mode of variability in the ocean-atmosphere system, and influences rainfall over much of the globe, including southern Africa. ${ }^{23,24}$ Numerous indices of the ENSO phenomenon have been derived, but a simple average of SSTs over the area $5^{\circ} \mathrm{N}-5^{\circ} \mathrm{S}, 170^{\circ}-120^{\circ} \mathrm{W}$, known as the Niño3.4 region, ${ }^{25}$ is widely used because of its conceptual simplicity and ease of calculation. Monthly SST data for the Niño3.4 region were used as an index of the ENSO phenomenon. Only a three-month (December-February [DJF]) average was considered. The SSTs were obtained from http:// www.cpc.ncep.noaa.gov/data/indices/sstoi.indices, which is updated in near-real time.

Analysis. To separate the impact of non-climate related trends and the policy intervention on the incidence data from the possible impact of climatic trends, we modeled the relationships in a stepwise regression with log malaria incidence as the dependent variable and CMAP rainfall, policy intervention $(0,1)$, year, as well as two interaction variables [year $\times((1-$ policy intervention $)$ and policy intervention $)]$, as the independent variables. The stepwise criterion for entry into the model was $<0.05$, and the criterion for removing a variable from the model was $>0.10$. Including year in the model allows us to separate trend in the data from inter-annual variability, while including the policy intervention enables us to distinguish changes around the mean as a function of the intervention. The two interaction variables (IVs) are included to assess trends before and after the policy change (IV before 1997 and IV from 1997 onwards). The regression was recalculated including $\mathrm{CMAP}^{2}$ because of an a priori assumption that the relationship of rainfall to malaria may not be linear.

The regression coefficients for year and policy intervention were then used to subtract the impact of these two factors from the time series and the resultant standardized data set was used for further analysis. The mean of the 22-year time series of standardized data was subtracted from each year to produce a standardized data set for annual anomalies in malaria incidence (1982-2003). This anomaly data set was then correlated with the estimated national averaged rainfall anomalies using Spearman's rank order and Pearson's product moment correlation coefficients. Correlations with SST obtained from the Niño3.4 region were also studied. Confidence intervals $(95 \%)$ for the correlations were calculated using 10,000 bootstrap samples. Two other statistical tests were used to confirm the robustness of our results: logistic regression was used to determine which of the climate variables tested were significant predictors of anomalous malaria years (defined using the higher and lower quartiles of standardized malaria incidence anomalies), and Mann-Whitney U tests were conducted to assess the significance of the difference in estimated malaria incidence using the rainfall model for high and low observed malaria incidence anomalies. The $\mathrm{U}$ test is a non-parametric version of the more widely used $t$-test for differences between means. ${ }^{26}$

\section{RESULTS}

Rainfall accumulations from December onwards were significant predictors of log-confirmed malaria incidence. Rainfall for DJF consistently gave the best results and was used in all subsequent analyses.

Both linear and quadratic inter-annual variability models included rainfall as the primary predictor of log malaria incidence (Tables 1 and 2). The policy intervention $(0,1)$ and the interaction variable (IV before 1997) were also significant predictors in both models. Although the linear model (Table 1) explained more than $75 \%$ of the inter-annual variance, the use of a quadratic relationship between CMAP rainfall and $\log$ malaria incidence is supported by a significant improvement in model fit (approximately 85\% of variance explained; Table 2), and by further evidence presented below.

The observed rainfall for DJF 2000, including that associated with tropical cyclone Eline, ${ }^{27}$ was the highest observed during the study period but resulted in lower than expected malaria incidence. This may have been due to flushing out of vector breeding sites by the heavy rains, but no information is available to support this line of reasoning. It may also have been due to the heightened state of alert of the Ministry of Health, which repeated the annual indoor residual insecticide spray round immediately after tropical cyclone Eline had passed. In case the non-linear nature of the relationship between CMAP DJF and malaria incidence anomalies was largely due to results for 2000 , we repeated the analysis without the 2000 data and plotted the new regression line on the entire dataset (Figure 3). There was very little difference between the models with and without 2000 data, indicating that the quadratic nature of the relationship of malaria anomalies to rainfall was robust (as supported by the bootstrap results

TABLE 1

Non-climate and linear climate related inter-annual variability in log malaria incidence*

\begin{tabular}{|c|c|c|c|}
\hline Model & $\mathrm{R}$ & $\mathrm{R}^{2}$ & Adjusted $\mathrm{R}^{2}$ \\
\hline 1 & $0.730 \dagger$ & 0.53 & 0.51 \\
\hline 2 & $0.840 \neq$ & 0.71 & 0.68 \\
\hline 3 & $0.89 \S$ & 0.79 & 0.75 \\
\hline \multicolumn{4}{|c|}{$\begin{array}{l}\text { * CMAP }=\text { Climate Prediction Center Merged Analysis of Precipitation; DJF = Decem- } \\
\text { ber-February. } \\
\text { † Predictors: constant, CMAP DJF. } \\
\$ \text { Predictors: constant, CMAP DJF, policy intervention }(0,1) . \\
\S \text { Predictors: constant, CMAP DJF, policy intervention }(0,1), \text { policy-year interaction vari- } \\
\text { able (year } \times(1 \text { - policy intervention), policy intervention). }\end{array}$} \\
\hline
\end{tabular}


TABLE 2

Non-climate and quadratic climate related inter-annual variability in $\log$ malaria incidence*

\begin{tabular}{|c|c|c|c|}
\hline Model & $\mathrm{R}$ & $\mathrm{R}^{2}$ & Adjusted $\mathrm{R}^{2}$ \\
\hline 1 & $0.73 \dagger$ & 0.53 & 0.51 \\
\hline 2 & $0.81 \ddagger$ & 0.65 & 0.61 \\
\hline 3 & $0.87 \S$ & 0.75 & 0.710 \\
\hline 4 & $0.94 \pi$ & 0.88 & 0.85 \\
\hline \multicolumn{4}{|c|}{$\begin{array}{l}\text { * For definitions of abbreviations, see Table } 1 . \\
\dagger \text { Predictors: constant CMAP DJF. } \\
\ddagger \text { Predictors (constant) CMAP DJF, CMAP DJF. } \\
\S \text { Predictors (constant) CMAP DJF, CMAP DJF }{ }^{2} \text { policy intervention }(0,1) . \\
\text { II Predictors (constant) CMAP DJF, CMAP DJF }{ }^{2} \text { policy intervention }(0,1) \text {, policy-year } \\
\text { interaction variable (year } \times(1-\text { policy intervention). }\end{array}$} \\
\hline
\end{tabular}

reported below). On the basis of these observations, all subsequent analyses were conducted assuming a quadratic relationship between rainfall and malaria incidence.

The coefficients for policy intervention and the interaction variable (IV before 1997) from the quadratic CMAP model were used to calculate a separate variable indicative on nonclimatic trends and the effect of the policy intervention. This variable was considered an index of vulnerability. A standardized malaria incidence variable was then calculated by subtracting the vulnerability index from the annual log malaria incidence data. Subtracting the mean value of this standardized variable data resulted in standardized malaria incidence anomalies that were used in subsequent analyses (Figure 4 and Table 3).

Having removed the effects of trends in vulnerability and the policy intervention, we assessed the importance of climate variability in determining the residual variance in malaria incidence. More than $70 \%$ of this residual variance was found to be correlated with a quadratic model of nationally averaged seasonal rainfall for DJF (Figure 5 and Table 3). The quadratic nature of this relationship is supported by the $95 \%$ bootstrap confidence intervals for the regression parameters (linear CMAP parameter $=4.66$ [2.19-7.49] and quadratic CMAP parameter $=-0.60[-1.11$ to -0.17$]$, i.e., random

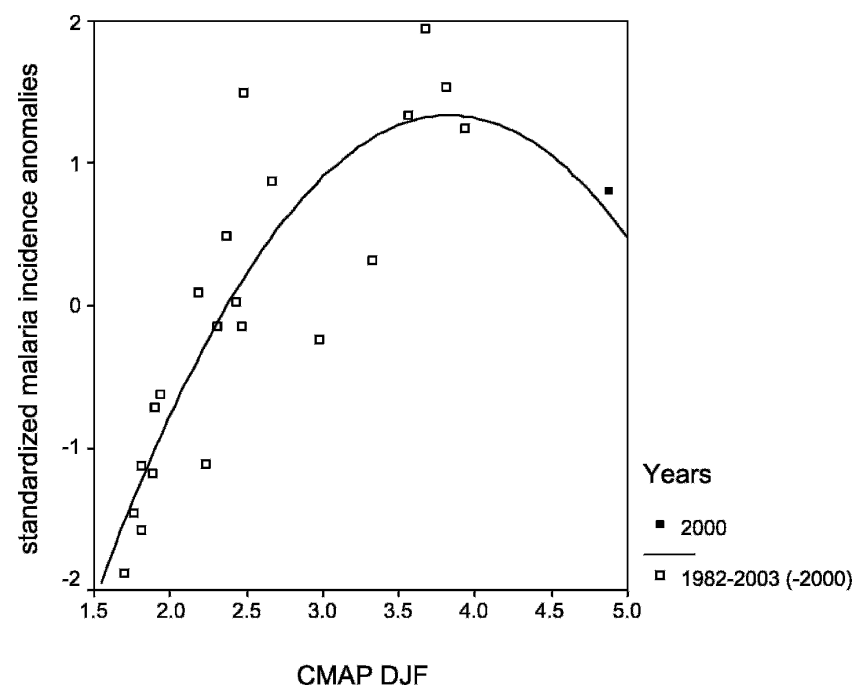

FIgURE 3. Quadratic relationship of Climate Prediction Center Merged Analysis of Precipitation (CMAP) for December-February (DJF) to confirmed standardized malaria incidence anomalies (without using year 2000 in model development).

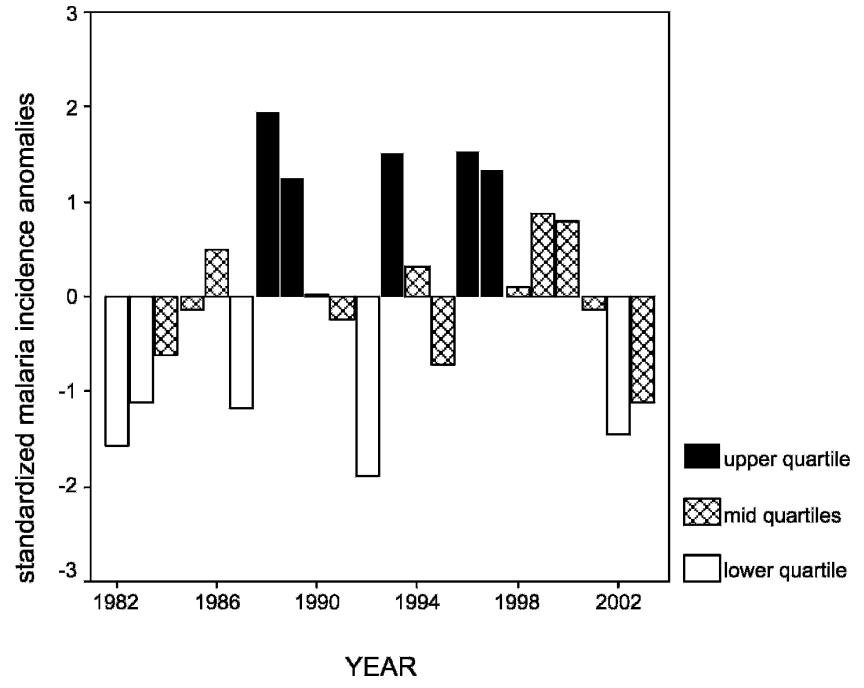

FIGURE 4. Confirmed standardized malaria incidence anomalies for Botswana, 1982-2003.

samples from the 22-year period had a consistent and similar quadratic form; specifically, the coefficient for the quadratic term was consistently less than 0 ).

Anomalously high and low standardized malaria incidence anomalies were defined using the higher and lower quartiles of the dataset (highest and lowest five years), respectively. Logistic regression was used to ascertain the predictability of each quartile using the CMAP quadratic model (Figure 6). The analysis was supported using the Mann-Whitney U test to establish whether the rainfall quantities differ given high or low malaria.

The CMAP quadratic model successfully discriminated the low and high malaria anomaly years (Table 4). The relationship was strongest for the lower malaria quartile, the driest five years corresponding with the lowest malaria anomalies. High malaria years were also successfully discriminated with the exception of 1993, where high malaria was associated with a just about average rainfall season (1992-1993). However, it should be noted that this epidemic followed a devastating drought (1991-1992) that was associated with the most negative malaria anomaly of the 22-year period (Figure 4).

We found that negative anomalies in Niño 3.4 DJF SSTs were significantly associated with positive CMAP DJF (Pearson's $\mathrm{R}=-0.55[-0.76$ to -0.22$]$ and Spearman's $\mathrm{R}=-0.59$ $[-0.81$ to -0.18$])$, as well as with the standardized malaria incidence anomalies (Table 3 ), and accounted for nearly $25 \%$ of inter-annual variance in malaria incidence. The relationship for malaria was not improved when $\mathrm{SST}^{2}$ was included in the analysis. The $95 \%$ bootstrap confidence intervals for the regression parameter (linear SST parameter $=-0.51[-0.84$ to -0.19$])$ further support the robustness of this relationship, as do the results of the Mann-Whitney $U$ test and logistic regression (Table 4).

\section{DISCUSSION}

Detailed studies of the interaction of rainfall and malaria in the general community in Africa are limited. There are many reasons for this deficiency. These include the general weak- 
TABLE 3

Relationship of standardized malaria incidence anomalies CMAP and SSTs*

\begin{tabular}{|c|c|c|c|c|}
\hline Year & $\begin{array}{l}\text { Vulnerability } \\
\text { anomalies }\end{array}$ & $\begin{array}{l}\text { Standardized malaria } \\
\text { incidence anomalies }\end{array}$ & $\begin{array}{c}\text { CMAP DJF } \\
\text { quadratic model }\end{array}$ & SST DJF \\
\hline 1982 & -1.46 & $-1.57 \dagger$ & -1.19 & 0.11 \\
\hline 1983 & -1.3 & $-1.12 \dagger$ & -1.24 & 2.68 \\
\hline 1984 & -1.14 & -0.62 & -0.96 & -0.69 \\
\hline 1985 & -0.98 & -0.14 & 0.17 & -1.19 \\
\hline 1986 & -0.82 & 0.50 & -0.04 & -0.61 \\
\hline 1987 & -0.66 & $-1.18 \dagger$ & -1.01 & 1.32 \\
\hline 1988 & -0.5 & $1.95 \ddagger$ & 1.24 & 0.82 \\
\hline 1989 & -0.34 & $1.25 \ddagger$ & 1.38 & -1.83 \\
\hline 1990 & -0.18 & 0.02 & 0.11 & 0.07 \\
\hline 1991 & -0.02 & -0.24 & 1.01 & 0.39 \\
\hline 1992 & 0.14 & $-1.88 \dagger$ & -1.42 & 1.91 \\
\hline 1993 & 0.3 & $1.50 \ddagger$ & 0.08 & 0.24 \\
\hline 1994 & 0.46 & 0.32 & 1.3 & 0.09 \\
\hline 1995 & 0.62 & -0.72 & -1.04 & 1.07 \\
\hline 1996 & 0.78 & $1.54 末$ & 1.33 & -0.84 \\
\hline 1997 & 0.72 & $1.33 \neq$ & 1.3 & -0.44 \\
\hline 1998 & 0.72 & 0.10 & -0.39 & 2.51 \\
\hline 1999 & 0.72 & 0.87 & 0.43 & -1.53 \\
\hline 2000 & 0.72 & 0.80 & 0.64 & -1.65 \\
\hline 2001 & 0.72 & -0.14 & -0.13 & -0.74 \\
\hline 2002 & 0.72 & $-1.45 \dagger$ & -1.33 & -0.02 \\
\hline 2003 & 0.72 & -1.11 & -0.24 & 1.22 \\
\hline Pearson's correlation§ & & & $0.88(0.76-0.96)$ & $-0.49(-0.79$ to -0.21$)$ \\
\hline Spearman's correlation $\S$ & & & $0.89(0.70-0.97)$ & $-0.48(-0.78$ to -0.08$)$ \\
\hline
\end{tabular}

ness of the health information systems in most African countries, the lack of diagnostic facilities resulting in a paucity of extended times series of confirmed case data, and difficulties in accessing appropriate rainfall data for the specific locations and time periods for which case data are available. Furthermore, studies on the interaction between climate and malaria have focused in recent years on the potential role of climate change in determining recent increases in malaria transmission in highland areas in $\mathrm{Africa}^{28}$ where temperature rather than rainfall has been the parameter of greatest interest. ${ }^{29-31}$

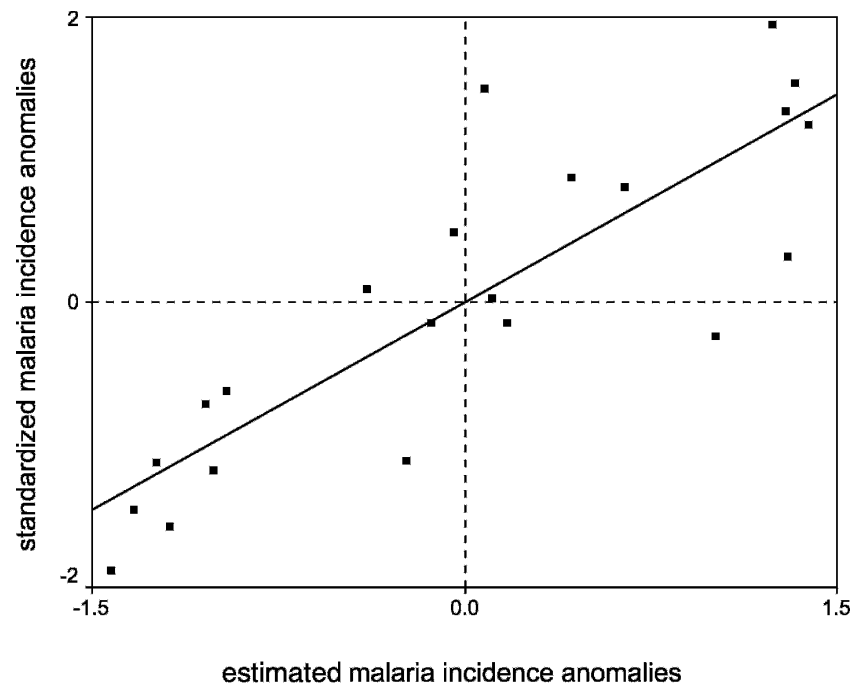

FIGURE 5. Relationship of confirmed standardized malaria incidence anomalies and predicted values from the Climate Prediction Center Merged Analysis of Precipitation quadratic model.
These studies have served to highlight the significant methodologic difficulties in undertaking such analyses. ${ }^{32}$ Recently, Craig and others studied the relationship between climatic and non-climatic factors and a 30-year time series of malaria case data in KwaZulu-Natal, South Africa. ${ }^{33}$ They found significant linear relationships between seasonal changes in case totals and mean maximum daily temperatures (JanuaryOctober) of the preceding season, and total rainfall in the current summer months of November-March. A combination of these climatic factors explained approximately $30-50 \%$ of the variance in differential case numbers depending on the climate data source used. Although climate appears to account for much less of the variance of malaria in KwaZula Natal than in Botswana (where a quadratic function of rainfall alone accounted for more than $60 \%$ of standardized malaria incidence anomalies), it is interesting to note that key high malaria years in KwaZulu-Natal area, e.g., 1988, 1993, 1996, and 2000, also correspond with high malaria anomaly years in Botswana, suggesting that regional rather than local processes are likely to be responsible for much of the interannual variation.

In addition, what has emerged most clearly from our and other studies ${ }^{33}$ is that changes in population vulnerability as a function of a wide range of processes, (e.g., population dynamics, co-infection, and drug and insecticide resistance) are potentially major causes of trends in malaria case numbers and must be accounted for at least en masse if the impact of variability and climate change on malaria incidence are to be accurately assessed. Such assessments are a necessary part of developing evidence-based malaria early warning systems.

Malaria incidence increased steadily during the first 15 years of the period under study (1982-1996) despite an active control program. Previous studies of inter-annual variability 


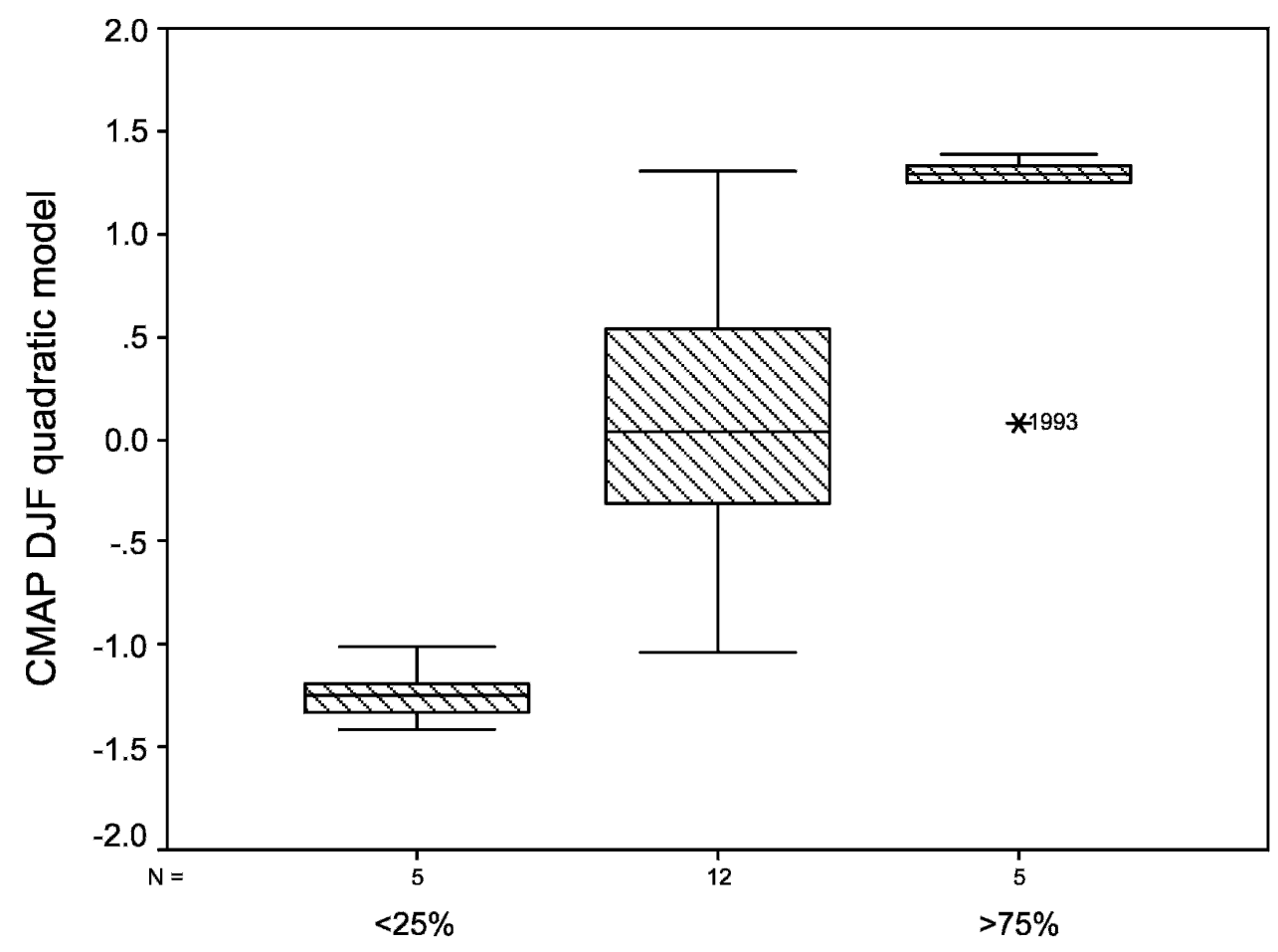

\section{Standardized malaria incidence anomaly quartiles}

FIgURE 6. Confirmed standardized malaria incidence anomaly quartiles and Climate Prediction Center Merged Analysis of Precipitation (CMAP) December-February (DJF) quadratic model. The box length is the interquartile range. * = extremes: cases with values more than three box lengths from the upper or lower edge of the box.

in malaria and climate parameters have either ignored the impact of underlying trends in the analysis ${ }^{34}$ or have assumed that all trend in the data is not climate related. ${ }^{32}$ Here we have used multivariate regression to calculate the underlying trends (the vulnerability index) while controlling for possible climate trends. In the early 1980s, Botswana was engulfed in a regional drought that not only reduced malaria transmission, and therefore herd immunity, but meant that when the rains returned in 1988 the lack of preparedness in the Ministry of Health resulted in high case numbers and a high case fatality rate ${ }^{21}$ (Figure 1). Changes in parasite sensitivity to chloroquine, a southward movement in the belt of transmission, and increasing prevalence of human immunodeficiency virus $^{35}$ may all have contributed to the trend in incidence. Once the malaria data are standardized, the impact of rainfall on inter-annual variability in malaria incidence in this epidemic region in Africa can be clearly identified. The relationship is non-linear with a plateau of annual incidence occurring with national averaged rainfall, estimated by CMAP to be between 3.5 and $4.0 \mathrm{~mm} /$ day. Consistent results were obtained with each methodology confirming the robustness of our findings. The SSTs were also found to be significantly correlated with standardized malaria incidence anomalies, suggesting that the latter may be partly predicted from seasonal climate forecasts (Figure 7). Because of the shortness of the time series (22 years) and the need to include information on underlying trend and a policy intervention, we used a number of different methods (parametric and non-parametric) to test the strength of our results.

The southern African region has a long and varied history of malaria control with the occurrence of periodic epidemics. $^{4,20}$ The countries of the Southern African Development

TABLE 4

Relationship of standardized malaria incidence anomalies CMAP and SSTs with bootstrap confidence limits (CLs)*

\begin{tabular}{|c|c|c|c|c|c|}
\hline & $\begin{array}{c}\text { Malaria } \\
\text { anomalies }\end{array}$ & Test statistic & $P$ & $\begin{array}{l}\text { Lower } \\
\text { CL }\end{array}$ & Upper \\
\hline \multirow{4}{*}{$\begin{array}{l}\text { CMAP DJF } \\
\text { quadratic model }\end{array}$} & \multirow[t]{2}{*}{ Lower } & Mann-Whitney U test & $<0.001$ & $<0.001$ & $<0.001$ \\
\hline & & Logistic regression & $<0.001$ & $<0.001$ & $<0.001$ \\
\hline & \multirow[t]{2}{*}{ Upper } & Mann-Whitney U test & $<0.001$ & $<0.001$ & 0.060 \\
\hline & & Logistic regression & 0.006 & $<0.001$ & $>0.999$ \\
\hline \multirow[t]{4}{*}{ SST DJF } & \multirow[t]{2}{*}{ Lower } & Mann-Whitney U test & 0.019 & $<0.001$ & 0.271 \\
\hline & & Logistic regression & 0.087 & $<0.001$ & 0.713 \\
\hline & \multirow[t]{2}{*}{ Upper } & Mann-Whitney U test & 0.179 & 0.001 & 0.876 \\
\hline & & Logistic regression & 0.144 & $<0.001$ & 0.920 \\
\hline
\end{tabular}

\footnotetext{
* For definitions of abbreviations, see Tables 1 and 3.
} 


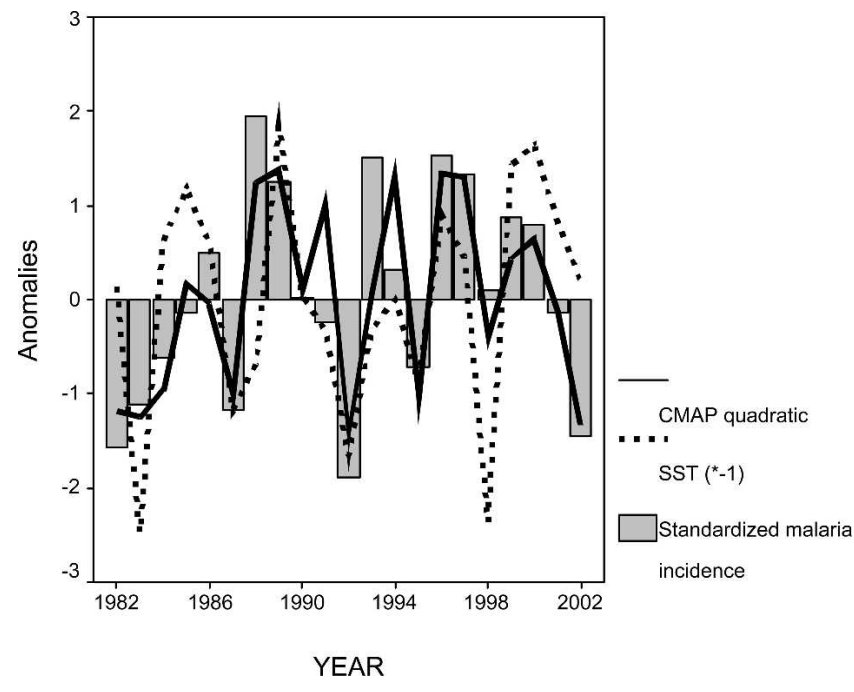

FIGURE 7. Anomalies in December-February sea surface temperature (SST), Climate Prediction Center Merged Analysis of Precipitation quadratic, and confirmed standardized malaria incidence for the period 1982-2003. SST $(*-1)=$ SST $\times-1$ (inverse of SST).

Community are committed to the Abuja Targets for Roll Back Malaria in Africa, and this includes improved detection and response to epidemics. To meet these targets, countries are expected to detect $60 \%$ of malaria epidemics within two weeks of onset, and respond to $60 \%$ of epidemics within two weeks of their detection. The countries recognize that to achieve these targets they need improved information on when and where epidemics are most likely to occur. As a consequence, the regions malaria control services are actively engaged in the development of climate-based malaria early warning. ${ }^{36}$ Our results provide evidence in support of regional policy because they demonstrate a strong impact of DJF rainfall on standardized malaria incidence anomalies at the national level. When combined with information on the malaria trend (an indicator of vulnerability to increased malaria disease), the rainfall information provides warning of high transmission years prior to the peak malaria transmission season (March-April) and can thereby alert the Ministry of Health to increased epidemic risk. It may be possible to provide even earlier warnings of changes in malaria risk on the basis of seasonal rainfall forecasts. Further work is required to assess the relationship of climate variables (including temperature) to standardized malaria incidence at smaller spatial scales in Botswana.

An important outcome of this analysis is that our results suggest that climate since the year 2000 has contributed to the recent success of the malaria control program in reducing malaria incidence and highlights the need for vigilance should less favorable rainfall occur in the future. These results therefore demonstrate the importance of including the confounding effects of climate variability on incidence in the measurements of achievement of malaria targets ${ }^{37}$ if we are to get a true assessment of whether malaria is being rolled back.

Received December 1, 2004. Accepted for publication January 11, 2005.

Acknowledgments: We thank the World Health Organization Southern Africa Inter-Country Programme in Zimbabwe and the Na- tional Malaria Control Unit in Botswana for their help with this study. We also thank Francisco Doblas-Reyes, Renate Hagedorn, Andrew Morse, and Tim Palmer for helpful discussions.

Financial support: This work was initially supported by the United Kingdom's Department for International Development subsequently Malaria Knowledge Programme, the Liverpool School of Tropical Medicine, and a cooperative agreement with the National Oceanic and Atmospheric Administration (NOAA) (NA07GP0213).

Disclaimer: The views herein contained are those of the authors and do not necessarily reflect the views of either the Department for International Development, NOAA, or any of their sub-agencies.

Authors' addresses: Madeleine C. Thomson, Simon J. Mason, and Stephen J. Connor, International Research Institute for Climate Prediction, The Earth Institute at Columbia University, Monell Building, 61 Route 9W, Lamont Campus, Palisades, NY 10964-8000, Telephone: 845-680-4413, Fax: 845-680-4864, E-mails: mthomson@ iri.columbia.edu,simon@iri.columbia.edu, and sjconnor@ iri.columbia.edu. Thandie Phindela, National Malaria Control Programme, Epidemiology and Disease Control Unit, Ministry of Health, Private Bag 00269, Gaborone, Botswana, E-mail: phindela@info.bw

\section{REFERENCES}

1. Worrall E, Rietveld A, Delacollette C, 2004. The burden of malaria epidemics and cost-effectiveness of interventions in epidemic situations in Africa. Am J Trop Med Hyg 71 (Suppl 2): 136-140.

2. Connor S, Thomson M, Molyneux D, 1999. Forecasting and prevention of epidemic malaria: new perspectives on an old problem. Parassitologia 41: 439-448.

3. WHO, 2002. Final Report on the Third Meeting of the RBM Technical Resource Network on Epidemic Prevention and Control. Geneva: World Health Organization.

4. WHO, 2003. Chapter 3: Prompt and Effective Treatment. Africa Malaria Report. Geneva: World Health Organization.

5. Koenraadt CJM, Githeko AK, Takken W, 2004. The effects of rainfall and evapotranspiration on the temporal dynamics of Anopheles gambiae s.s. and Anopheles arabiensis in a Kenyan village. Acta Trop 90: 141-153.

6. Lindsay SW, Bodker R, Malima R, Msangeni HA, Kisinza W, 2000. Effect of 1997-98 El Nino on highland malaria in Tanzania. Lancet 355: 989-990.

7. Najera JA, Kouznetzsov R, L., Delacollette, C., 1998. Malaria Epidemics: Detection and Control, Forecasting and Prevention. Geneva: World Health Organization. WHO/MAL/98.1084.

8. Thomson MC, Connor SJ, O'Niell K, Meert JP, 2000. Environmental information for epidemic prediction. Parasitol Today 16: $137-138$.

9. Rogers DJ, Randolph SE, Snow RW, Hay SI, 2002. Satellite imagery in the study and forecast of malaria. Nature 415: 710-715.

10. Ceccato P, Connor SJ, Jeanne I, Thomson MC, 2005. Application of geographical information system and remote sensing in malaria risk. Parassitologia 47: (in press).

11. Gill CA, 1923. The prediction of malaria epidemics: with special reference to an actual forecast in 1921. Indian J Med Res 10: $1136-1143$.

12. Hay SI, Rogers DJ, Shanks GD, Myers MF, Snow RW, 2001. Malaria early warning in Kenya. Trends Parasitol 17: 95-99.

13. Thomson MC, Connor SJ, 2001. The development of malaria early warning systems for Africa. Trends Parasitol 17: 438-445.

14. WHO, 2001. Malaria Early Warning Systems, Concepts, Indicators and Partners, "A Framework for Field Research in Africa." Geneva: World Health Organization.

15. Goddard L, Mason SJ, 2002. Sensitivity of seasonal climate forecasts to persisted SST anomalies. Climate Dynamics 19: 619631.

16. Kovats RS, Bouma MJ, Hajat S, Worrall E, Haines A, 2003. El Nino and health. Lancet 362: 1481-1489.

17. Mason SJ, Tyson PD, 2000. The occurrence and predictability of droughts over southern Africa. Wilhite DA, ed. Droughts. Volume 1. A Global Assessment. New York: Routledge, 113-134. 
18. de Meillon B, 1947. The Anophelini of the Ethiopian Geographical Region. Johannesburg, South Africa: The South African Institute for Medical Research.

19. Ministry of Health, Botswana, 1999. A Manual for Health Workers in Botswana. Gaborone: Epidemiology and Disease Control Unit, Community Health Services Division, Ministry of Health, Botswana, 78.

20. Mabaso MLH, Sharp B, Lengeler C, 2004. Historical review of malarial control in southern African with emphasis on the use of indoor residual house-spraying. Trop Med Int Health 9: 846856.

21. Ministry of Health, Botswana, 1997. Report on Malaria Conference 27-29 August 1997. Gaborone: Malaria Control Programme, Ministry of Health, 96.

22. Xie P, Arkin PA, 1998. Global monthly precipitation from satellite-observed outgoing longwave radiation. J Climate 11: 137164.

23. Goddard L, Mason SJ, Zebiak SE, Ropelewski CF, Basher R, Cane MA, 2001. Current approaches to seasonal-tointerannual climate predictions. Int J Climatol 21: 1111-1152.

24. Mason SJ, Jury MR, 1997. Climatic variability and change over southern Africa: a reflection on underlying processes. Prog Phys Geogr 21: 23-50.

25. Barnston AG, Chelliah M, Goldenberg SB, 1997. Documentation of a highly ENSO-related SST region in the equatorial Pacific. Atmosphere-Ocean 35: 367-383.

26. Sheskin DJ, 2000. Handbook of Parametric and Nonparametric Statistical Procedures. Boca Raton, FL: Chapman and Hall/ CRC Press.

27. Reason CJC, Keibel A, 2004. Tropical cyclone Eline and its unusual penetration and impacts over the southern African mainland. Weather Forecasting 19: 789-805.

28. Lindsay SW, Martens WJM, 1998. Malaria in the African high- lands: past, present and future. Bull World Health Organ 76: $33-45$.

29. Loevinsohn ME, 1994. Climatic warming and increased malaria incidence in Rwanda. Lancet 343: 714-718.

30. Hay SI, Rogers DJ, Randolph SE, Stern DI, Cox J, Shanks GD, Snow RW, 2002. Hot topic or hot air? Climate change and malaria resurgence in east African highlands. Trends Parasitol 18: $530-534$.

31. Zhou G, Minakawa N, Githeko AK, Yan G, 2004. Association between climate variability and malaria epidemics in the east African highlands. Proc Natl Acad Sci U S A 101: 2375-2380.

32. Bouma MJ, 2003. Methodological problems and amendments to demonstrate effects of temperature on the epidemiology of malaria. A new perspective on the highland epidemics in Madagascar, 1972-89. Trans R Soc Trop Med Hyg 97: 133-139.

33. Craig MH, Kleinschmidt I, Le Sueur D, Sharp BL, 2004. Exploring 30 years of malaria case data in KwaZulu-Natal, South Africa: Part II. The impact of non-climatic factors. Trop Med Int Health 9: 1258-1266.

34. Hay SI, Myers MF, Burke DS, Vaughn DW, Endy T, Ananda N, Shanks GD, Snow RW, Rogers DJ, 2000. Etiology of interepidemic periods of mosquito-borne disease. Proc Natl Acad Sci U S A 97: 9335-9339.

35. Salomon JA, Murray CJL, 2001. Modelling HIV/AIDS epidemics in sub-Saharan Africa using seroprevalence data from antenatal clinics. Bull World Health Organ 79: 596-607.

36. da Silva J, Garanganga B, Teveredzi V, Marx S, Mason SJ, Connor SJ, 2004. Improving epidemic malaria planning, preparedness and response in southern Africa. Malaria J 3: 37.

37. Remme JHF, Binka F, Nabarro D, 2001. Toward a framework and indicators for monitoring Roll Back Malaria. Am J Trop Med Hyg 64: 76-84. 